\title{
Germination of several wheat cultivars in desert soil after amendment with raw and digested poultry manure with and without combination with mineral fertilizer
}

\author{
Hassan El-Zeadani ${ }^{1} \cdot$ Jamal Abubaker $^{2}$ (D) Mohemed Essalem $^{1} \cdot$ Alsanousi Alghali $^{1}$
}

Received: 9 February 2018 / Accepted: 8 September 2018 / Published online: 15 September 2018

(c) The Author(s) 2018

\begin{abstract}
Purpose This study aimed to investigate the effect of time interval between sowing and amendment with non-digested and digested poultry manure and their combinations with urea on the germination of three wheat cultivars (Slambo, Acsad, and Karim) in the desert soil.

Methods The cultivars were sown on four different dates, i.e. directly, 10, 20 and 30 days after amendment. Fertilizers were applied at a rate of $350 \mathrm{~kg}$ Tot $\mathrm{N} \mathrm{ha}^{-1}$. The germinated seeds were recorded daily starting at day 4 after sowing until day 14 after which the following germination attributes were calculated: time to reach $50 \%$ germination $\left(T_{50 \%}\right)$, final germination percentage (FGP) and germination index (GI). Additionally, radicle length, plumule length and seedling dry weight were also determined.

Results Sowing near to the application delayed and reduced seeds germination particularly in the treatments amended with non-digested and digested manure in combination urea. This was confirmed by all germination attributes, i.e. high values of $T_{50 \%}$ and low values of FGP and GI. Moreover, sowing near to the application reduced the length of plumule and radicle as well as decreased seedling dry weight of all wheat cultivars.

Conclusion Results suggested that prolonging the period between amendments and sowing to 20 or 30 days would give better germination attributes and increase plumule and radicle length plus increasing seedling dry weight.
\end{abstract}

Keywords Seed germination $\cdot$ Digestate $\cdot$ Poultry manure $\cdot$ Urea $\cdot$ Wheat cultivars

\section{Introduction}

Desert soil is by far the predominant soil in the southern part of Libya, where grain crops such as barley and wheat are cultivated under sprinkler irrigation. Wheat (Triticum aestivum

Jamal Abubaker

jamal_abubaker@hotmail.com

Hassan El-Zeadani

has64b@gmail.com

Mohemed Essalem

alzain2010@yahoo.com

Alsanousi Alghali

sanoealmosleh@gmail.com

1 Department of Crops, Faculty of Agriculture, Sabha University, P. O. Box 18758, Sabha, Libya

2 Department of Soil and Water, Faculty of Agriculture, Sabha University, P. O. Box 18758, Sabha, Libya
L.) occupies the first rank in Libya in terms of cultivated area, i.e. about 165,000 ha with an annual yield of 200,000 tons (Alabasi et al. 2017). In this region, wheat yield is far below the optimal due to the fertility of desert soils is low to provide the crop with the essential plant nutrients. Therefore, the application of fertilizers to this soil is necessary to improve its productivity. Urea is the most widely used chemical nitrogenous fertilizer in Libya, although several studies have shown that it is not good for improving soil properties (Angus et al. 2014; Lungu and Dynoodt 2008). Therefore, replacing chemical fertilizers with organic fertilizers or combine it with organic fertilizers is required to improve soil fertility. Numerous studies have reported that the application of organic fertilizers to soils of arid and semiarid regions enhances significantly soil fertility through improving soil properties compare to application of mineral fertilizers (Diacono and Montemurro 2010; Elhadi et al. 2016; Elnesairy et al. 2016; Hati et al. 2006). Organic fertilizers such as animal manures have a considerable amount of nutrients in organic form and hence is not immediately 
available to the plant until decomposition by heterotrophic soil microorganisms occurs (Ladd and Jackson 1982). In fact, due to the dryness and the absence of soil organic matter, desert soils have a low microbial activity to breakdown organic components and release plant nutrients (Angel et al. 2013; Makhalanyane et al. 2015). It has been reported that microbial communities of the desert soil have higher relative abundances of genes associated with dormancy and lower abundances associated with the nutrient release (Fierer et al. 2012). Therefore, anaerobic digestion of animal manure before application to the soil might be an effective way to increase nutrient availability to the plant. Several studies have shown that fertilizing soils with digested manure results in higher yields compare to compost and mineral fertilizers (Abubaker et al. 2012, 2017; Abubaker 2012). Anaerobic digestion is used worldwide to sustain waste management and produce bioenergy (Angelidaki and Ahring 2000). Moreover, anaerobic digestion leads to the generation of residues called digestate that rich in mineralized plant nutrients (Makádi et al. 2012; Möller and Müller 2012; Odlare et al. 2011). Although, digested and non-digested organic waste has a positive effect on crop yield, however, some other studies have reported an adverse effect of these materials on wheat seeds germination. Abubaker et al. (2017) reported that the application of digestate and non-digested to desert soil, especially in the combination with urea delayed and reduced the germination of wheat seeds. In another study by Bacilio et al. (2003) showed that the composts generated from dairy cow manure have inhibitory effects on wheat seed germination. This negative effect has been attributed to the contaminants that generated during decomposition of organic waste such as ethylene oxide (Wong et al. 1983) and organic acid (Bacilio et al. 2003; Makádi et al. 2012). Moreover, the concentration of ammonia in digestate is high (GarcíaGonzález et al. 2016) and this can reduce and delay wheat seeds germination (Bremner and Krogmeier 1989; Wan et al. 2016). In fact, it is unclear if this adverse effect will last for a short or long period and thus can be avoided by adjusting the cultivation strategy, e.g. prolonging the period between application and sowing. The objective of present study was to investigate the influence of time interval between sowing and application of non-digested and anaerobically digested poultry manure with and without combination with urea on the germination of three wheat cultivars in desert soil.

\section{Materials and methods}

\section{Soil sampling and description}

Sandy topsoil $(0-20 \mathrm{~cm})$ was collected from desert area that has not been cultivated or fertilized before, located at Sabha city, a southern part of Libya $\left(22^{\circ} 30^{\prime} \mathrm{N}, 10^{\circ} \mathrm{E}\right)$. After sampling, the soil transported to the laboratory where it was cleaned, sieved (4-mm screen) and stored at lab temperature $\left(20 \pm 3{ }^{\circ} \mathrm{C}\right)$. Physical and chemical characteristics of the soil are shown in Table 1. Percentage of sand, silt, and clay was determined according to Bouyoucos (1962). The water-holding capacity of the soil was measured according to Forster (1995). Soil pH was measured in the suspension at a soil-to-deionized water ratio of 1:2 using a pH meter 3030 (Jenway, Ltd., UK). Electrical conductivity (ECe) was determined in a 1:1 (v/v) water-to-soil suspension using the conductivity meter (model 4070, ELE, England). Soil organic matter content (OM) was measured according to Ball (1964). Total soil nitrogen (Tot N) was determined using Kjeldahl technique modified by Bradstreet (1954). Total soil carbon (Tot C) was analysed by a loss-on-ignition method described by Dean (1974). Soil phosphorus (P) was extracted according to the method described by Chapman and Pratt (1961) and determined using Cecil CE 202 spectrophotometer at 420 nm (Super Aquarius, Cecil Instruments, Cambridge, England). Potassium (K) and sodium ( $\mathrm{Na}$ ) were measured using a flame photometer (Jenway, PFP7, UK) according to Protocol: P05-001A and Protocol: P05-002A, respectively. Soil magnesium $(\mathrm{Mg})$ and calcium $(\mathrm{Ca})$ were determined by atomic absorption spectrometer (AAS, Analytik Jena AG 400) according to the methods of Ramakrishna et al. (1966).

\section{Non-digested, digested manure and urea}

Approximately $30 \mathrm{~kg}$ of poultry manure was collected from broiler farm located in Sabha city, a southern part of Libya. In this farm, wood shavings were used as bedding and grinded grain (i.e. wheat, barley, corn, and soybeans)

Table 1 Physical and chemical properties of the soil used in the germination experiment

\begin{tabular}{ll}
\hline Parameters & Values \\
\hline Physical properties & \\
Sand (\%) & 97 \\
Clay (\%) & 1.3 \\
Silt (\%) & 1.7 \\
Water-holding capacity (\%) & 21.5 \\
Chemical properties & \\
$\mathrm{pH}$ & \\
$\mathrm{Easte}$ & 8.2 \\
$\mathrm{OM}(\%)$ & 2.8 \\
Tot N $(\%)$ & 0.4 \\
Tot C $(\%)$ & 0.09 \\
$\mathrm{P}\left(\mathrm{g} \mathrm{kg}^{-1} \mathrm{dw}\right)$ & 0.89 \\
$\mathrm{~K}\left(\mathrm{~g} \mathrm{~kg}^{-1} \mathrm{dw}\right)$ & 0.07 \\
$\mathrm{Na}\left(\mathrm{g} \mathrm{kg}^{-1} \mathrm{dw}\right)$ & 0.08 \\
$\mathrm{Mg}\left(\mathrm{g} \mathrm{kg}^{-1} \mathrm{dw}\right)$ & 0.25 \\
$\mathrm{Ca}\left(\mathrm{g} \mathrm{kg}^{-1} \mathrm{dw}\right)$ & 0.05 \\
\hline
\end{tabular}


as nutriment. The collected manure transported to the laboratory where it was cleaned, portioned and stored at room temperature $\left(20 \pm 3{ }^{\circ} \mathrm{C}\right)$ until use. The manure was solid and almost dry contains only $2 \%$ of moisture. The digestion of manure was performed anaerobically in a sealable plastic container (30 L volume) provided with a regulator in the lid letting the flow of air from the container and prevents back-flow into it. The digestion started by adding a manure to deionized water at a ratio of $6: 10$ after which the container sealed. The anaerobic digestion was operated at the mesophilic temperature $\left(42-48{ }^{\circ} \mathrm{C}\right)$ for 30 days retention time, after which the container opened and digested manure portioned into small plastic bags, and stored at $-18 \pm 3{ }^{\circ} \mathrm{C}$ until use. The physical and chemical characteristics of fertilizers are shown in Table 2. Dry matter (DM) was determined using oven drying at $100{ }^{\circ} \mathrm{C}$ for $24 \mathrm{~h}$ as described by Windham et al. (1987). The $\mathrm{pH}$ was determined at a manureto-deionized water ratio of 1:6 using a pH meter 3030 (Jenway, Ltd., UK). Tot $\mathrm{N}$ was measured by the Kjeldahl method according to Bradstreet (1954). Tot $C$ was measured by a loss-on-ignition method according to Dean (1974). Tot P was extracted by $\mathrm{HNO}_{3}$ according to Pungor and Horval (1994) and determined using Cecil CE 202 spectrophotometer at $420 \mathrm{~nm}$ (Super Aquarius, Cecil Instruments, Cambridge, England). Tot $\mathrm{K}$ was extracted by $\mathrm{HCl}$ (Protocol: P05-004A) and analysed by the flame photometer (Jenway, $\mathrm{PFP} 7, \mathrm{UK})$. The mineral fertilizer used in the experiment was urea $\left(\mathrm{CO}\left(\mathrm{NH}_{2}\right)_{2}\right)$ composed of $20 \% \mathrm{C}, 26.6 \% \mathrm{O}, 46.6 \%$ $\mathrm{N}, 6.7 \% \mathrm{H}$.

\section{Treatments}

The germination experiment was performed in a plastic dishes $(7.5 \mathrm{~cm}$ diam. $\times 5 \mathrm{~cm}$ height $)$ at the research farm of the faculty of agriculture, Sabha University, Libya. The experiment consisted of five fertilizers, three wheat cultivars (Slambo, Acsad, and Karim) and four sowing dates. Six treatments were used in the experiment showing in Table 3. The experiment was set up in a random block design with

Table 2 Physical and chemical characteristics of non-digested and digested poultry manure used in germination experiment

\begin{tabular}{lll}
\hline Parameters & Non-digested manure & $\begin{array}{l}\text { Digested } \\
\text { manure }\end{array}$ \\
\hline $\mathrm{DM}(\%)$ & 98 & 15.2 \\
$\mathrm{pH}$ & 9.3 & 9.7 \\
$\operatorname{Tot} \mathrm{N}\left(\mathrm{g} \mathrm{kg}^{-1} \mathrm{dw}\right)$ & 42.6 & 46.2 \\
$\operatorname{Tot} \mathrm{C}\left(\mathrm{g} \mathrm{kg}^{-1} \mathrm{dw}\right)$ & 470 & 395 \\
$\mathrm{C} / \mathrm{N}$ & 11 & 9 \\
Tot P $\left(\mathrm{g} \mathrm{kg}^{-1} \mathrm{dw}\right)$ & 14.2 & 13.9 \\
Tot K $\left(\mathrm{g} \mathrm{kg}^{-1} \mathrm{dw}\right)$ & 3.9 & 18 \\
\hline
\end{tabular}

four replicates of each treatment, resulting in a total of 252 dishes. The fertilizers were applied at a rate corresponding to $350 \mathrm{~kg}$ Tot $\mathrm{N} \mathrm{ha}^{-1}$. At the start, $200 \mathrm{~g}$ of soil were weighted into each dish and amended with target fertilizer, after that sprayed with $15 \mathrm{ml}$ of distilled water. The combination with mineral fertilizers was applied so that a $50 \%$ of the applied $\mathrm{N}$ came from the manure and $50 \%$ came from the urea. The dishes were irrigated every other day.

\section{Sowing and germination attributes}

Four sets of dishes were prepared, each set contains 60 dishes in total 240 dishes (fertilized) +12 unfertilized dishes were used as control (control was run only at the first sowing). The first set was sowed directly after amendment, the second set sowed 10 days after amendment, the third set sowed 20 days after amendment and the fourth set sowed 30 days after amendment. Each dish was sowed with 15 seeds at the depth of $1 \mathrm{~cm}$ (broken and small seeds were avoided), i.e. corresponding to a sown rate of $170 \mathrm{~kg}$ seeds ha ${ }^{-1}$. Before the start of the experiment, all wheat cultivars were tested for their vitalities according to Ellis et al. (1985), which were $99 \pm 4,89 \pm 6$ and $95 \pm 3$ for Slambo, Karim and Acsad, respectively. After sowing, all dishes were placed on trolleys under controlled condition $(13 \mathrm{~h}$ day, $11 \mathrm{~h}$ night, temperature $20 \pm 2{ }^{\circ} \mathrm{C}$ and air humidity $34 \%$ ). The sowed dishes were checked daily and germinated seeds were counted at day 4, 6, 8, 9, 12 and 14 from sowing. From the germination counts, several germination attributes were calculated including time to reach $50 \%$ germination $\left(T_{50 \%}\right)$, final germination percentage (FGP) and germination index (GI). $T_{50 \%}$ was calculated according to the formula of Coolbear et al. (1984) modified by Farooq et al. (2005). FGP and GI were calculated according to the formulas described by Dastanpoor et al. (2013). At the end of the experiment (day 14), seedlings were carefully removed from the soil by placing them in flat pans of water where radicles could be freed from soil particles with little injury. After that, the length of plumule and radicle of each seedling was measured. In the

Table 3 Treatments used in the germination experiment

\begin{tabular}{lll}
\hline No. & Abbreviations & Treatments \\
\hline 1 & $\mathrm{C}$ & No fertilization \\
2 & $\mathrm{U}$ & Urea \\
3 & $\mathrm{PM}$ & Non-digested poultry manure \\
4 & $\mathrm{PM}+\mathrm{U}$ & Non-digested poultry manure \\
& & $(50 \% \mathrm{~N})+$ urea $(50 \% \mathrm{~N})$ \\
5 & DPM & Digested poultry manure \\
6 & DPM+U & Digested poultry manure \\
& & $(50 \% \mathrm{~N})+$ urea $(50 \% \mathrm{~N})$ \\
\hline
\end{tabular}


end, seedling dry weight in each treatment was determined after drying in the oven at $75^{\circ} \mathrm{C}$ for $24 \mathrm{~h}$.

\section{Statistical analyses}

The obtained data were analysed using the SPSS (WIN. Version 17) procedure GLM multiple variables, where two-way ANOVA followed by Tukey (HSD) multiple comparison tests were used for repeated testing of paired differences between treatments regarding $T_{50 \%}$, FGP, GI, plumule length, radicle length and seedling dry weight, where time of sowing, fertilizer type, wheat cultivars and their interactions were considered as fixed factors. The dataset was unbalanced as it contained only one set of control running at first sowing. Differences considered significant at $p<0.05$ unless otherwise not stated.

\section{Results}

\section{Germination attributes}

Application of non-digested and digested poultry manure especially in combination with $\mathrm{U}$ had delayed and reduced the germination of the three wheat cultivars considerably in the first and second sowing. However, in the third and fourth sowing, the germination enhanced markedly. This adverse effect was confirmed by all germination attributes i.e. high values of $T_{50 \%}$ and low values of FGP and GI. The analysis of variance showed that the germination of wheat seeds was mostly affected by fertilizer type and sowing date rather than wheat cultivars. Statistical analysis showed significant $(p<0.05)$ effect of sowing date and fertilizer type on $T_{50 \%}$, FGP and GI. Whereas the effect of wheat cultivars was only significant $(p<0.05)$ on FGP but not on the other germination attributes. Moreover, the analysis of variance showed significant $(p<0.05)$ interaction effect of sowing date $\times$ fertilizer type and fertilizer type $\times$ wheat cultivars on all germination attributes. Whereas, the interaction effect of sowing date $\times$ fertilizer type $\times$ wheat cultivars was only significant $(p<0.05)$ on FGP but not on the other germination attributes.

\section{Time to reach $50 \%$ germination}

$T_{50 \%}$ represent estimated time for cumulative germination to reach $50 \%$ of its maximum (Table 4 ). In treatments amended with $\mathrm{U}, T_{50 \%}$ was significantly $(p<0.05)$ shorter in the fourth sowing ranged from $3.8 \pm 1.2$ to $4.7 \pm 1.4$ for all wheat cultivars compared to other sowing dates where it ranged from $4.4 \pm 0.8$ to $7.6 \pm 2.0$ (Table 4). Treatments amended with PM $+\mathrm{U}, \mathrm{DPM}$ and DPM $+\mathrm{U}$ significantly $(p<0.05)$ reduced $T_{50 \%}$ (ranged from $2.5 \pm 0.9$ to $3.6 \pm 1.0$ ) on the fourth sowing for all wheat cultivars compared to first, second and third sowing (ranged from $3.3 \pm 0.6$ to $10.3 \pm 3.8$ ). Moreover, at the first sowing PM treatments gave lower $T_{50 \%}$ by all wheat cultivars ranged from $3 \pm 0.0$ to $3.7 \pm 1.2$ compared to treatments amended with $\mathrm{U}$, $\mathrm{PM}+\mathrm{U}, \mathrm{DPM}$ and $\mathrm{DPM}+\mathrm{U}$ (ranged from $3.8 \pm 0.6$ to $10.3 \pm 3.8)$.

\section{Final germination percentage}

FGP reached its maximum in $U$ treatments at the first and fourth sowing (ranging from $70 \pm 10$ to $93 \pm 6 \%$ ) while in the second and third sowing was lower (ranging from $60 \pm 0$ to $77 \pm 6 \%$ ) (Table 5). Treatments amended with PM and DPM showed higher FGP in the first sowing compared to treatments amended with $\mathrm{PM}+\mathrm{U}$ and $\mathrm{DPM}+\mathrm{U}$ with exception of that Karim cultivar had lower FGP in PM treatment (Table 5).

Moreover, FGP for Slambo cultivar was significantly $(p<0.05)$ low in the treatment amended with DPM $+\mathrm{U}$ compared to treatment amended with $\mathrm{PM}+\mathrm{U}$ in the first sowing. At the second, third and fourth sowing FGP increased significantly $(p<0.05)$ in both $\mathrm{PM}+\mathrm{U}$ and $\mathrm{DPM}+\mathrm{U}$ treatments without any significant differences between them. Moreover, in the treatments sowed with Acsad and Karim cultivars, it seems PM + U had lowered their FGP significantly $(p<0.05)$ compared to the application of DPM $+\mathrm{U}$ in the first sowing. Overall, FGP had increased significantly $(p<0.05)$ in the fourth sowing compared to the other sowing dates, where they have reached their maximum (100\%) especially for Slambo and Acsad cultivars.

\section{Germination index}

GI represent germination speed, low values mean slower germination and higher values mean faster germination. GI has increased significantly $(p<0.05)$ in $\mathrm{U}$ treatments in the fourth sowing date compared to the other sowing dates by all wheat cultivars with exception of Karim cultivar where no significant difference was detected between the first and fourth sowing (Table 6). In the third and fourth sowing, GI increased significantly $(p<0.05)$ (ranged from $7.5 \pm 1.4$ to $19.4 \pm 1.9$ ) in most treatments amended with $\mathrm{PM}, \mathrm{PM}+\mathrm{U}$, $\mathrm{DPM}$ and DPM + U (Table 6). Furthermore, in the first and second sowing GI had decreased in the treatments amended with $\mathrm{PM}+\mathrm{U}$ and $\mathrm{DPM}+\mathrm{U}$ compared with treatments amended with PM and DPM by all wheat cultivars. Moreover, the results demonstrated that Slambo cultivar had higher GI compared to other wheat cultivars in most treatments and at most sowing dates. 
Table 4 The time to reach $50 \%$ germination $\left(T_{50 \%}\right)$ of three wheat cultivars (Slambo, Acsad and Karim) after 14 days growing period sown in desert soil on four sowing dates after amendment with non-digested and anaerobically digested poultry manure with and without combination with urea

\begin{tabular}{llclll}
\hline Fertilizer type & Wheat cultivars & \multicolumn{2}{l}{$T_{50 \%}$ (days) } & & \\
\cline { 2 - 5 } & & First sowing & Second sowing & Third sowing & Fourth sowing \\
\hline C & Slambo & $5.7 \pm 1.3$ & - & - & - \\
C & Acsad & $5.6 \pm 0.6$ & - & - & - \\
C & Karim & $3.4 \pm 0.6$ & - & - & - \\
Urea & Slambo & $7.6 \pm 2.0$ & $5.0 \pm 1.1$ & $4.4 \pm 0.8$ & $3.8 \pm 1.2$ \\
Urea & Acsad & $5.9 \pm 1.4$ & $5.5 \pm 1.9$ & $5.0 \pm 1.4$ & $3.8 \pm 1.4$ \\
Urea & Karim & $6.4 \pm 1.1$ & $5.6 \pm 3.6$ & $5.4 \pm 1.2$ & $4.7 \pm 1.4$ \\
PM & Slambo & $3.0 \pm 0.0$ & $4.3 \pm 2.2$ & $6.6 \pm 1.6$ & $3.8 \pm 1.4$ \\
PM & Acsad & $3.4 \pm 0.8$ & $5.3 \pm 2.0$ & $4.6 \pm 2.7$ & $4.4 \pm 1.3$ \\
PM & Karim & $3.7 \pm 1.2$ & $4.5 \pm 0.9$ & $4.0 \pm 0.0$ & $4.8 \pm 1.6$ \\
PM+U & Slambo & $9.1 \pm 0.9$ & $3.3 \pm 0.6$ & $4.3 \pm 0.7$ & $3.0 \pm 0.0$ \\
PM+U & Acsad & $10.3 \pm 3.8$ & $4.3 \pm 2.2$ & $4.4 \pm 1.2$ & $3.6 \pm 1.0$ \\
PM+U & Karim & $9.2 \pm 3.3$ & $6.5 \pm 0.5$ & $4.2 \pm 1.0$ & $3.0 \pm 0.0$ \\
DPM & Slambo & $4.0 \pm 0.0$ & $4.1 \pm 1.0$ & $4.0 \pm 0.9$ & $2.5 \pm 0.9$ \\
DPM & Acsad & $3.8 \pm 0.6$ & $4.0 \pm 0.9$ & $4.3 \pm 1.3$ & $3.0 \pm 0.0$ \\
DPM & Karim & $5.0 \pm 0.9$ & $3.8 \pm 1.4$ & $3.6 \pm 0.8$ & $3.4 \pm 0.8$ \\
DPM+U & Slambo & $7.3 \pm 1.2$ & $7.0 \pm 0.0$ & $4.7 \pm 0.4$ & $3.0 \pm 1.4$ \\
DPM + U & Acsad & $7.9 \pm 2.6$ & $6.6 \pm 2.2$ & $4.2 \pm 1.0$ & $3.0 \pm 0.0$ \\
DPM + U & Karim & $5.1 \pm 2.7$ & $7.0 \pm 1.0$ & $4.2 \pm 1.0$ & $3.4 \pm 1.4$ \\
\hline
\end{tabular}

Values represent the average \pm standard deviation $(n=4)$

- no control used in the second, third and fourth sowing

\begin{tabular}{llclll}
\hline Fertilizer type & Wheat cultivars & FGP $(\%)$ & & & \\
\cline { 3 - 6 } & & First sowing & Second sowing & Third sowing & Fourth sowing \\
\hline C & Slambo & $88 \pm 1.4$ & - & - & - \\
C & Acsad & $93 \pm 2.5$ & - & - & - \\
C & Karim & $88 \pm 6.3$ & - & - & - \\
Urea & Slambo & $93 \pm 6$ & $63 \pm 15$ & $67 \pm 6$ & $93 \pm 12$ \\
Urea & Acsad & $70 \pm 10$ & $73 \pm 6$ & $60 \pm 0$ & $83 \pm 6$ \\
Urea & Karim & $90 \pm 17$ & $70 \pm 17$ & $77 \pm 6$ & $90 \pm 10$ \\
PM & Slambo & $93 \pm 12$ & $100 \pm 0$ & $93 \pm 12$ & $100 \pm 0$ \\
PM & Acsad & $100 \pm 0$ & $93 \pm 12$ & $100 \pm 0$ & $100 \pm 0$ \\
PM & Karim & $60 \pm 0$ & $87 \pm 12$ & $80 \pm 0$ & $87 \pm 12$ \\
PM + U & Slambo & $80 \pm 20$ & $93 \pm 12$ & $100 \pm 0$ & $100 \pm 0$ \\
PM+U & Acsad & $60 \pm 0$ & $73 \pm 23$ & $100 \pm 0$ & $100 \pm 0$ \\
PM +U & Karim & $47 \pm 12$ & $73 \pm 12$ & $100 \pm 0$ & $87 \pm 12$ \\
DPM & Slambo & $93 \pm 12$ & $93 \pm 12$ & $100 \pm 0$ & $100 \pm 0$ \\
DPM & Acsad & $100 \pm 0$ & $93 \pm 12$ & $100 \pm 0$ & $100 \pm 0$ \\
DPM & Karim & $93 \pm 12$ & $87 \pm 12$ & $100 \pm 0$ & $93 \pm 12$ \\
DPM $+\mathrm{U}$ & Slambo & $53 \pm 23$ & $93 \pm 12$ & $100 \pm 0$ & $100 \pm 0$ \\
DPM $+\mathrm{U}$ & Acsad & $73 \pm 12$ & $67 \pm 31$ & $100 \pm 0$ & $93 \pm 12$ \\
DPM + U & Karim & $80 \pm 0$ & $80 \pm 0$ & $87 \pm 23$ & $87 \pm 23$ \\
\hline
\end{tabular}

Values represent the average \pm standard deviation $(n=4)$

- no control used in the second, third and fourth sowing
Table 5 Final germination percentage (FGP) of three wheat cultivars (Slambo, Acsad and Karim) after 14 days growing period sown in desert soil on four sowing dates after amendment with non-digested and anaerobically digested poultry manure with and without combination with urea 
Table 6 Germination index (GI) of three wheat cultivars (Slambo, Acsad and Karim) after 14 days growing period sown in desert soil on four sowing dates after amendment with non-digested and anaerobically digested poultry manure with and without combination with urea

\begin{tabular}{llrlll}
\hline Fertilizer type & Wheat cultivars & GI $\left(\%\right.$ day $\left.^{-1}\right)$ & & \\
\cline { 2 - 5 } & & First sowing & Second sowing & Third sowing & Fourth sowing \\
\hline C & Slambo & $11 \pm 0.3$ & - & - & - \\
$\mathrm{C}$ & Acsad & $14 \pm 0.5$ & - & - & - \\
$\mathrm{C}$ & Karim & $15 \pm 1.5$ & - & - & - \\
Urea & Slambo & $13.9 \pm 0.8$ & $11.7 \pm 2.7$ & $8.4 \pm 2.0$ & $15.3 \pm 3.1$ \\
Urea & Acsad & $11.8 \pm 1.2$ & $12.5 \pm 0.8$ & $7.5 \pm 1.4$ & $13.0 \pm 2.0$ \\
Urea & Karim & $13.0 \pm 4.3$ & $10.8 \pm 3.0$ & $10.6 \pm 2.1$ & $14.7 \pm 2.9$ \\
PM & Slambo & $13.4 \pm 2.8$ & $16.7 \pm 0.0$ & $15.0 \pm 1.7$ & $15.8 \pm 0.8$ \\
PM & Acsad & $14.6 \pm 3.6$ & $12.9 \pm 1.6$ & $14.8 \pm 2.5$ & $16.7 \pm 1.7$ \\
PM & Karim & $11.7 \pm 0.5$ & $13.3 \pm 1.4$ & $12.5 \pm 0.0$ & $13.2 \pm 1.0$ \\
PM+U & Slambo & $7.9 \pm 2.4$ & $14.7 \pm 1.9$ & $19.4 \pm 1.9$ & $16.7 \pm 0.0$ \\
PM+U & Acsad & $4.7 \pm 0.3$ & $11.3 \pm 4.0$ & $17.8 \pm 1.0$ & $16.9 \pm 1.3$ \\
PM+U & Karim & $3.8 \pm 0.6$ & $10.1 \pm 1.7$ & $17.8 \pm 1.0$ & $14.2 \pm 1.4$ \\
DPM & Slambo & $15.0 \pm 1.4$ & $16.4 \pm 1.7$ & $18.3 \pm 1.7$ & $16.0 \pm 0.6$ \\
DPM & Acsad & $16.7 \pm 0.0$ & $17.2 \pm 3.5$ & $17.8 \pm 1.9$ & $16.4 \pm 0.5$ \\
DPM & Karim & $13.3 \pm 1.4$ & $13.5 \pm 1.4$ & $16.3 \pm 1.8$ & $16.7 \pm 3.3$ \\
DPM + U & Slambo & $5.7 \pm 1.0$ & $11.0 \pm 0.9$ & $16.7 \pm 0.0$ & $16.4 \pm 1.3$ \\
DPM + U & Acsad & $6.7 \pm 0.0$ & $7.6 \pm 3.6$ & $17.8 \pm 1.0$ & $15.6 \pm 1.9$ \\
DPM + U & Karim & $10.3 \pm 1.0$ & $10.6 \pm 1.0$ & $15.6 \pm 4.8$ & $17.5 \pm 4.6$ \\
\hline
\end{tabular}

Values represent the average \pm standard deviation $(n=4)$

- no control used in the second, third and fourth sowing

\section{Plumule and radicle length}

Analysis of variance showed significant $(p<0.05)$ effect of sowing date and fertilizer type on plumule and radicle lengths. Whereas wheat cultivars have significant $(p<0.05)$ effect only on radicle length. Moreover, there was significant $(p<0.05)$ interaction effect of sowing date $\times$ fertilizer type and fertilizer type $\times$ wheat cultivars on the plumule and radicle length. Whereas, radicle length was affected significantly $(p<0.05)$ by the interaction of sowing date $\times$ wheat cultivars and sowing date $\times$ fertilizer type $\times$ wheat varieties, but not the plumule length. The results displayed remarkable differences in the plumule and radicle length of seedlings obtained from the control compared to the results found in the other treatments (Fig. 1). In U treatments, plumule and radicle length were reduced significantly $(p<0.05)$ at all sowing dates in comparison with control, with the exception of plumule length of Slambo cultivar on the fourth sowing where showed no significant differences between $\mathrm{U}$ treatment and the control (Fig. 1). Amendment with $\mathrm{PM}+\mathrm{U}$ and $\mathrm{DPM}+\mathrm{U}$ significantly $(p<0.05)$ reduced plumule and radicle length at the first sowing for all wheat cultivars in comparison with treatments of PM, DPM, U and control (Fig. 1). However, in the second, third and fourth sowing plumule and radicle length increased significantly $(p<0.05)$ in the treatments of $\mathrm{PM}+\mathrm{U}$ and $\mathrm{DPM}+\mathrm{U}$ in comparison with the first sowing, $U$ treatments and control.

\section{Seedlings dry weight}

Analysis of variance displayed significant $(p<0.05)$ effect of sowing date, fertilizer type and wheat cultivars as well as their interaction on seedling dry weight. In the U treatments seedling dry weight was not improved significantly at the first, second and third sowing compared to the control with exception of Karim's which was significantly $(p<0.05)$ higher (Fig. 2). Furthermore, amendment with PM, PM+U, $\mathrm{DPM}$ and DPM + U did not improve seedling dry weight significantly on the first and second sowing in comparison with the control and $\mathrm{U}$ treatments. However, in the third and fourth sowing seedling dry weight has increased significantly $(p<0.05)$ for most wheat cultivars (Fig. 2).

\section{Discussion}

Several studies have shown that application of non-digested and digested manures enhanced wheat growth and yield particularly at combination with U (Abubaker et al. 2017; Kiani et al. 2005). However, in the present study, the germination of wheat cultivars was delayed and reduced when sowing was made directly or after 10 days from amendments with non-digested and digested manures. The adverse effect was more pronounced in the treatments amended with non-digested and digested manures in combination with urea as well as sole urea. This observation 

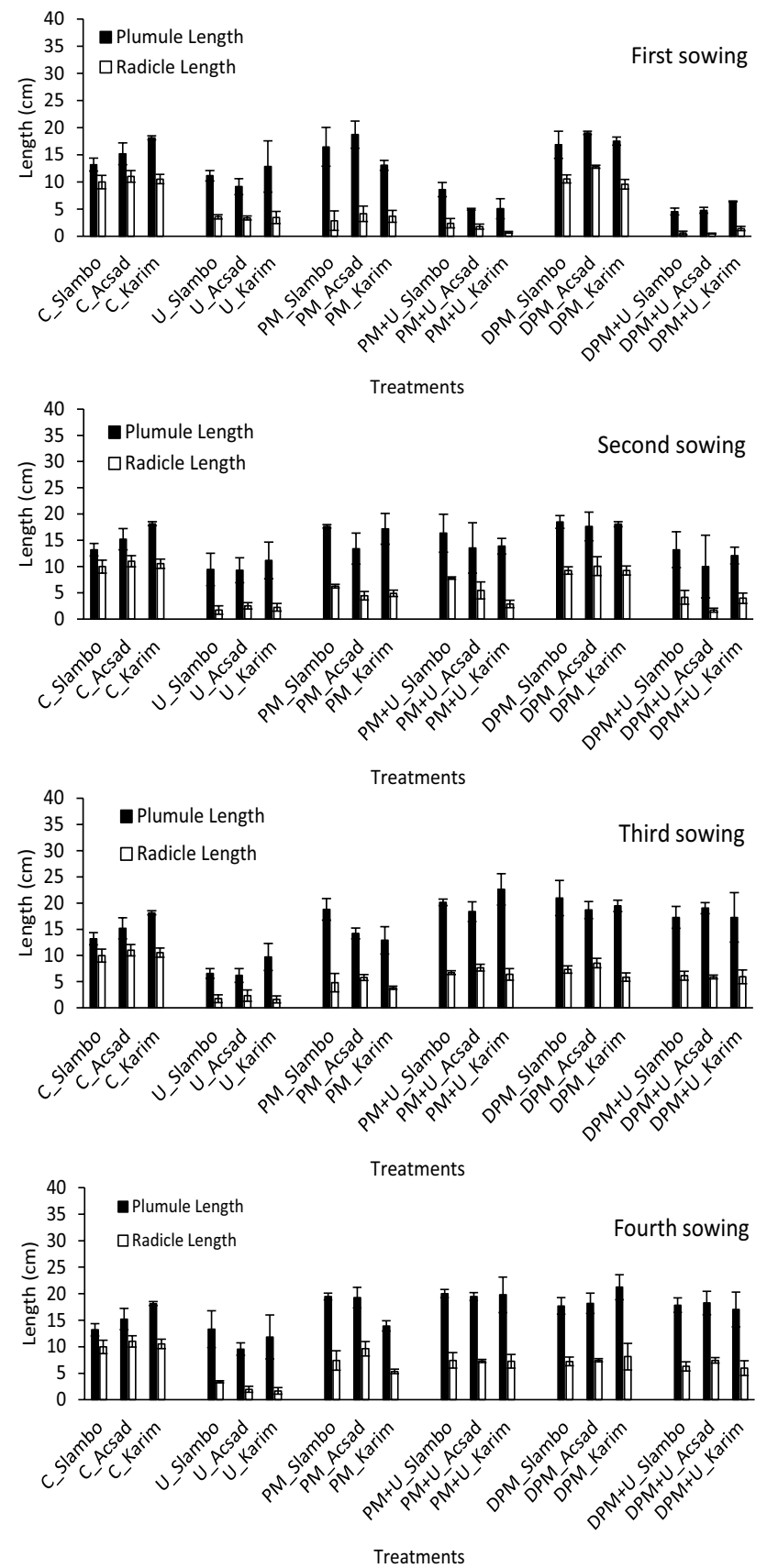

Fig. 1 Plumule and radicle length of three wheat cultivars (Slambo, Acsad and Karim) after 14 days growing period sown in desert soil on four sowing dates after amendment with non-digested and anaerobically digested poultry manure with and without combination with urea. Bars represent mean \pm standard deviation $(n=4)$

was in agreement with results reported by Abubaker et al. (2017) who found that sowing wheat seeds two days after amendment with non-digested and digested poultry manure with and without combination with urea reduced germination percentage considerably. Moreover, Gupta and Gupta (2011) reported a similar effect on okra seeds germination when sowing was performed 6 to $18 \mathrm{~h}$ after treatment
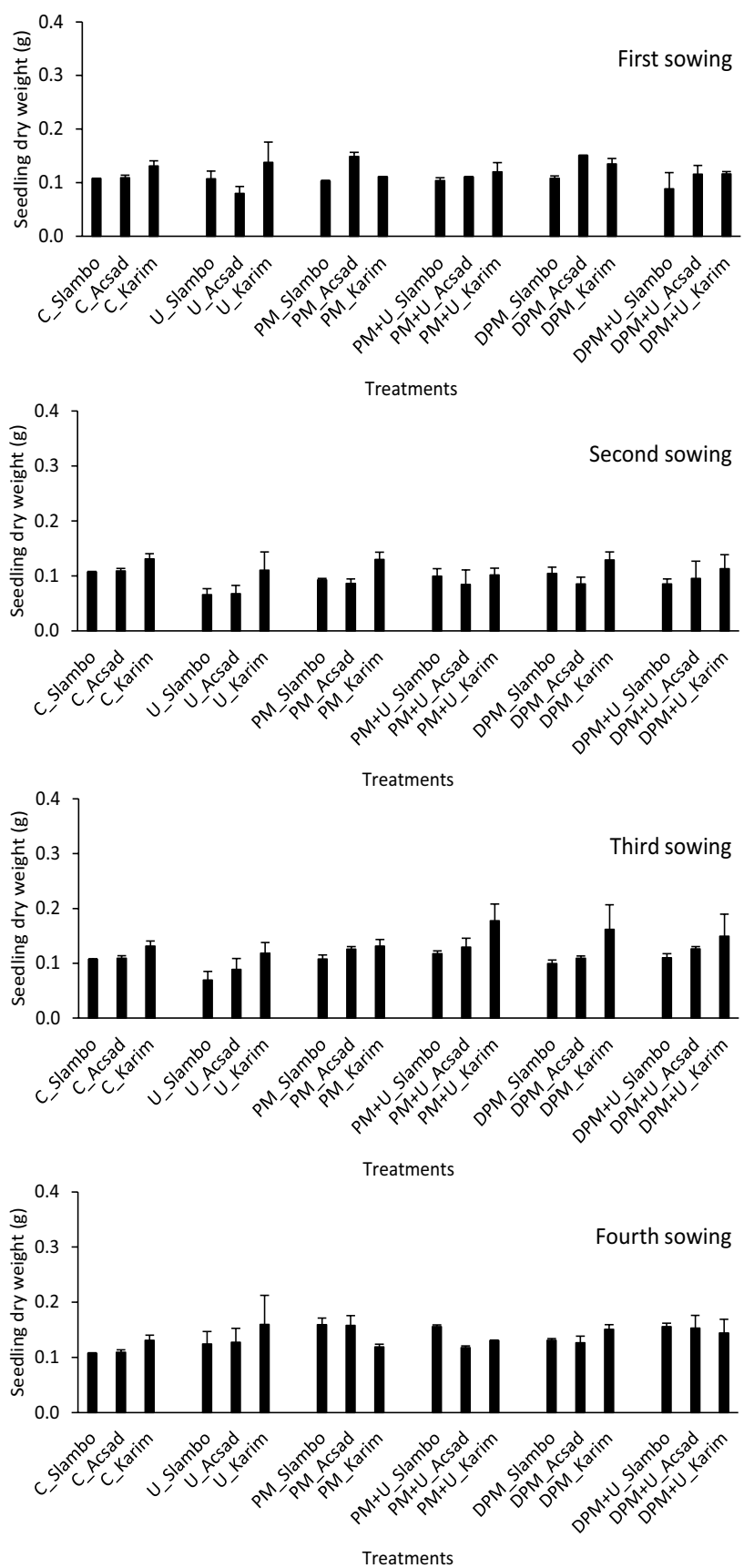

Fig. 2 Seedling dry weight of three wheat cultivars (Slambo, Acsad and Karim) after 14 days growing period sown in desert soil on four sowing dates after amendment with non-digested and anaerobically digested poultry manure with and without combination with urea. Bars represent mean \pm standard deviation $(n=4)$

with anaerobically digested poultry manure. This negative effect has been explained by the existence of humic acids in digested manure that formed during anaerobic digestion (Bacilio et al. 2003; Šerá and Novák 2011). In another study, Kaparaju et al. (2012) reported that anaerobically digested orange waste have a toxic effect on seeds germination of 
Chinese cabbage and they referred this toxicity to ammonia and organic acids in the digestate. Tunes et al. (2012) have reported that the presence of organic acids which originating from the anaerobic decomposition of organic material can significantly reduce the germination of wheat cultivars, radicle length and dry weight. It is well known that concentration of ammonia in digested manure is higher compared to raw manure (García-González et al. 2016), which was found to reduces wheat seed germination and suppresses root hair formation (Bremner and Krogmeier 1989; Wan et al. 2016). The adverse effect of combining manure with urea on seeds germination and radicle length have been reported in another study where they referred this adverse effect to the presence of ammonia, which formed through hydrolysis of urea by soil urease (Bremner and Krogmeier 1989). Moreover, Wan et al. (2016) have reported an inhibition effect of urea on seed germination and radicle growth in six wheat cultivars, they explained this effect by the formation of ammonia in the soil after application. Soil microorganisms can contribute to ammonia production in the soil by releasing ureases enzyme, which will convert urea to carbon dioxide and ammonia (Maier 2009). However, sowing seeds either 20 or 30 days after amendment enhanced seed germination, radicle length, plumule length and seedling dry weight. This probably was due to the degradation of fertilizers components and the transformation of mineral $\mathrm{N}$ by soil microorganisms (Powlson et al. 2001). Kuwatsuka and Shindo (1973) have reported that the concentration of phenolic substances in waste-treated soil decreased rapidly and reached that of the control on the day 30 after waste disposal. In addition, degradation of organic materials will also lead to the release of plant nutrients, which will enhance the growth of radicle and plumule resulted in increasing seedling dry weight. The present study showed that Acsad and Slambo cultivars had better germination percentages than those of Karim. This was probably due to their vitalities, which were higher for Slambo $(99 \pm 4 \%)$ and Acsad $(95 \pm 3 \%)$ compared to Karim $(89 \pm 6 \%)$.

\section{Conclusion}

It can be concluded that all tested fertilizers displayed short-term effects on wheat seeds germination, which can be avoided by applying fertilizer at least 20 days prior to the sowing. It seems to fertilize soil 20-30 days before sowing, can reduce the adverse effect of the substances that responsible for delayed germination in non-digested, digested poultry manure and urea. However, the early application of fertilizers, especially digestate, may cause the loss of nutrients such as $\mathrm{N}$ in the form of ammonia. Therefore, further work remains to evaluate the effect of prolonging the period between applications and sowing on wheat growth and yield.

Acknowledgements The authors are grateful to Sabha University for providing equipment and chemicals for the research.

Open Access This article is distributed under the terms of the Creative Commons Attribution 4.0 International License (http://creativeco mmons.org/licenses/by/4.0/), which permits unrestricted use, distribution, and reproduction in any medium, provided you give appropriate credit to the original author(s) and the source, provide a link to the Creative Commons license, and indicate if changes were made.

\section{References}

Abubaker J (2012) Effects of fertilisation with biogas residues on crop yield, soil microbiology and greenhouse gas emissions. Dissertation, Swedish University of Agricultural Sciences

Abubaker J, Risberg K, Pell M (2012) Biogas residues as fertiliserseffects on wheat growth and soil microbial activities. Appl Energy 99:126-134. https://doi.org/10.1016/j.apenergy.2012.04.050

Abubaker J, Elnesairy N, Ahmed S (2017) Effects of non-digested and anaerobically digested farmyard manures on wheat crop cultivated in desert soil. J Aridland Agric 3:1-10. https://doi.org/10.19071 /jaa.2017.v3.3127

Alabasi HAM, Mohamed Z, Abd Latif I, Bin Abdullah AM, Iliyas A (2017) Analysis of technical efficiency of traditional wheat farming in Fezzan region, Libya. J Agric Econ Rural Dev 3:251-258

Angel R, Pasternak Z, Soares MIM, Conrad R, Gillor O (2013) Active and total prokaryotic communities in dryland soils. FEMS Microbiol Ecol 86:130-138. https://doi.org/10.1111/1574-6941.12155

Angelidaki I, Ahring BK (2000) Methods for increasing the biogas potential from the recalcitrant organic matter contained in manure. Water Sci Technol 41:189-194

Angus JF, Gupta VVSR, Pitson GD, Good AJ (2014) Effects of banded ammonia and urea fertiliser on soil properties and the growth and yield of wheat. Crop Pasture Sci 65:337-352. https://doi. org/10.1071/CP13337

Bacilio M, Vazquez P, Bashan Y (2003) Alleviation of noxious effects of cattle ranch composts on wheat seed germination by inoculation with Azospirillum spp. Biol Fertil Soils 38:261-266. https://doi. org/10.1007/s00374-003-0650-1

Ball DF (1964) Loss-on-ignition as an estimate of organic matter and organic carbon in non-calcareous soils. J Soil Sci 15:84-92. https ://doi.org/10.1111/j.1365-2389.1964.tb00247.x

Bouyoucos GJ (1962) Hydrometer method improved for making particle size analyses of soils. Agron J 54:464-465. https://doi. org/10.2134/agronj1962.00021962005400050028x

Bradstreet RB (1954) Kjeldahl method for organic nitrogen. Anal Chem 26:185-187. https://doi.org/10.1021/ac60085a028

Bremner JM, Krogmeier MJ (1989) Evidence that the adverse effect of urea fertilizer on seed germination in soil is due to ammonia formed through hydrolysis of urea by soil urease. Proc Natl Acad Sci USA 86:8185-8188

Chapman HD, Pratt PF (1961) Methods of analysis for soils, plants, and waters. University of California, Department of Agricultural Sciences, Riverside

Coolbear P, Francis A, Grierson D (1984) The effect of low temperature pre-sowing treatment on the germination performance and membrane integrity of artificially aged tomato seeds. J Exp Bot 35:1609-1617. https://doi.org/10.1093/jxb/35.11.1609 
Dastanpoor N, Fahimi H, Shariati M, Davazdahemami S, Hashemi SMM (2013) Effects of hydropriming on seed germination and seedling growth in sage (Salvia officinalis L.). Afr J Biotechnol 12:1223-1228

Dean WE (1974) Determination of carbonate and organic matter in calcareous sediments and sedimentary rocks by loss on ignition; comparison with other methods. J Sediment Res 44:242-248. https://doi.org/10.1306/74d729d2-2b21-11d7-8648000102c1865d

Diacono M, Montemurro F (2010) Long-term effects of organic amendments on soil fertility. A review. Agron Sustain Dev 30:401-422. https://doi.org/10.1051/agro/2009040

Elhadi EA, Mubarak AR, Rezig FAM (2016) Effects of organic amendments on sand dune fixation. Int J Recycl Org Waste Agric 5:1-8. https://doi.org/10.1007/s40093-015-0111-5

Ellis RH, Hong TD, Roberts EH (1985) Handbook of seed technology for genebanks. Volume I. Principles and methodology. In: Handbooks for genebanks, no. 2, International Board for Plant Genetic Resources, Rome

Elnesairy N, Abubaker J, Mahmod H, Mukhtar N (2016) The impact of Bradyrhizobium, farmyard manure and inorganic nitrogen on growth and yield of guar. World J Agric Res 4:56-63. https://doi. org/10.12691/wjar-4-2-4

Farooq M, Basra SMA, Ahmad N, Hafeez K (2005) Thermal hardening: a new seed vigor enhancement tool in rice. J Integr Plant Biol 47:187-193. https://doi.org/10.1111/j.1744-7909.2005.00031.x

Fierer $\mathrm{N}$ et al (2012) Cross-biome metagenomic analyses of soil microbial communities and their functional attributes. Proc Natl Acad Sci USA 109:21390-21395. https://doi.org/10.1073/pnas.12152 10110

Forster JC (1995) Soil sampling, handling, storage and analysis A2. In: Alef K, Nannipieri P (eds) Methods in applied soil microbiology and biochemistry. Academic Press, London, pp 49-121. https:// doi.org/10.1016/B978-012513840-6/50018-5

García-González MC, Vanotti MB, Szogi AA (2016) Recovery of ammonia from anaerobically digested manure using gaspermeable membranes. Sci Agric 73:434-438. https://doi. org/10.1590/0103-9016-2015-0159

Gupta N, Gupta U (2011) Effect of anaerobically digested slurry of cow dung and kitchen waste on the seed quality in Okra (Abelmoschus esculentus L.). J Adv Lab Res Biol 2:1-3

Hati KM, Mandal KG, Misra AK, Ghosh PK, Bandyopadhyay KK (2006) Effect of inorganic fertilizer and farmyard manure on soil physical properties, root distribution, and water-use efficiency of soybean in Vertisols of central India. Bioresour Technol 97:21822188. https://doi.org/10.1016/j.biortech.2005.09.033

Kaparaju P, Rintala J, Oikari A (2012) Agricultural potential of anaerobically digested industrial orange waste with and without aerobic post-treatment. Environ Technol 33:85-94. https://doi. org/10.1080/09593330.2011.551839

Kiani MJ, Abbasi MK, Rahim N (2005) Use of organic manure with mineral $\mathrm{N}$ fertilizer increases wheat yield at Rawalakot Azad Jammu and Kashmir. Arch Agron Soil Sci 51:299-309. https:// doi.org/10.1080/03650340500069114

Kuwatsuka S, Shindo H (1973) Behavior of phenolic substances in the decaying process of plants: I. Identification and quantitative determination of phenolic acids in rice straw and its decayed product by gas chromatography. Soil Sci Plant Nutr 19:219-227. https:// doi.org/10.1080/00380768.1973.10432591

Ladd JN, Jackson RB (1982) Biochemistry of ammonification. In: Stevenson FJ (ed) Nitrogen in agricultural soils, vol 22. Agronomy monograph. American Society of Agronomy, Crop Science Society of America, Soil Science Society of America, Madison, pp 173-228. https://doi.org/10.2134/agronmonogr22.c5

Lungu OIM, Dynoodt RFP (2008) Acidification from long-term use of urea and its effect on selected soil properties. Afr J Food Agric Nutr Dev 8:63-76. https://doi.org/10.4314/ajfand.v8i1.19180

Maier RM (2009) Chapter 14-biogeochemical cycling. In: Maier RM, Pepper IL, Gerba CP (eds) Environmental microbiology, 2nd edn. Academic Press, San Diego, pp 287-318. https://doi.org/10.1016/ B978-0-12-370519-8.00014-6

Makádi M, Tomócsik A, Orosz V (2012) Digestate: a new nutrient source-review. InTech Eur. https://doi.org/10.5772/1793

Makhalanyane TP, Valverde A, Gunnigle E, Frossard A, Ramond J-B, Cowan DA (2015) Microbial ecology of hot desert edaphic systems. FEMS Microbiol Rev 39:203-221. https://doi.org/10.1093/ femsre/fuu011

Möller K, Müller T (2012) Effects of anaerobic digestion on digestate nutrient availability and crop growth: a review. Eng Life Sci 12:242-257. https://doi.org/10.1002/elsc.201100085

Odlare M, Arthurson V, Pell M, Svensson K, Nehrenheim E, Abubaker J (2011) Land application of organic waste-effects on the soil ecosystem. Appl Energy 88:2210-2218. https://doi.org/10.1016/j. apenergy.2010.12.043

Powlson D, Hirsch P, Brookes P (2001) The role of soil microorganisms in soil organic matter conservation in the tropics. Nutr Cycl Agroecosyst 61:41-51. https://doi.org/10.1023/A:1013338028454

Pungor E, Horval G (1994) Practical guide to instrumental analysis. CRC Press, Boca Raton

Ramakrishna TV, Robinson JW, West PW (1966) The determination of calcium and magnesium by atomic absorption spectroscopy. Anal Chim Acta 36:57-64. https://doi.org/10.1016/00032670(66)80006-5

Šerá B, Novák F (2011) The effect of humic substances on germination and early growth of Lamb's Quarters (Chenopodium album agg.). Biologia 66:470-476. https://doi.org/10.2478/s11756-011-0037-y

Tunes LMd, Avelar SAG, Barros ACSA, Pedroso DC, Muniz MFB, Menezes NLd (2012) Critical levels of organic acids on seed germination and seedling growth of wheat. Rev Bras Sementes 34:366-372. https://doi.org/10.1590/S0101-31222012000300002

Wan X, Wu W, Li C, Liu Y, Wen X, Liao Y (2016) Soil ammonia volatilization following urea application suppresses root hair formation and reduces seed germination in six wheat varieties. Environ Exp Bot 132:130-139. https://doi.org/10.1016/j.envex pbot.2016.08.010

Windham WR, Robertson JA, Leffler RG (1987) A Comparison of methods for moisture determination of forages for near infrared reflectance spectroscopy calibration and validation. Crop Sci 27:777-783. https://doi.org/10.2135/cropsci1987.0011183X00 2700040034x

Wong MH, Cheung YH, Cheung CL (1983) The effects of ammonia and ethylene oxide in animal manure and sewage sludge on the seed germination and root elongation of Brassica parachinensis. Environ Pollut Ecol Biol 30:109-123. https://doi. org/10.1016/0143-1471(83)90008-9

Publisher's Note Springer Nature remains neutral with regard to jurisdictional claims in published maps and institutional affiliations. 